UDC 341.492.1(497)

LBC 67.99(4Сла)

\title{
THE EFFECTIVENESS OF THE EU LAW APPLICATION BY NATIONAL COURTS OF THE SLOVAK REPUBLIC: CASE STUDY OF PRELIMINARY REFERENCES
}

\author{
Part One \\ M. Ondreychik \\ NGO “Society for Central and Eastern Europe”, Bratislava, Slovak Republic
}

\begin{abstract}
Introduction. The author examines the effectiveness of the procedure under Article 267 TFEU before national courts in the Slovak Republic in practice. The article deals with the practice of the CJEU on cases in which the questions were referred by the courts of general jurisdiction in the Slovak Republic. In terms of primary law and jurisprudence of CJEU, the national courts are obliged to cooperate with the CJEU to carry out the duties assigned to them in order to ensure that the interpretation and application of EU law are held in compliance with the Treaties. The author summarizes particular characteristics related to judicial practice of courts of general jurisdiction in the Slovak Republic. Methods. During the research, the author employs general scientific methods, such as analysis, comparison; on the other hand in the paper the formal-legal method is applied, as well. Results. The author analyzes the application of EU law by national courts in terms of preliminary references procedure in the Slovak Republic. Conclusions. On the basis of the information provided in the paper, it appears that apart from Supreme Court of the Slovak Republic, all courts of general jurisdiction have shown ineffective results within the preliminary references procedure that also raises doubts about the effectiveness of application of EU law by general courts of the Slovak Republic in general in situations when they consider the legal situation of hearing cases undeniable.

Key words: UN court, Treaty on UN functioning, Treaty on UN, national courts of the Slovak republic, judical practice of UN, preliminary reference.
\end{abstract}

УДК 341.492.1(497)

ББК 67.99(4Сла)

\section{ЭФФЕКТИВНОСТЬ ПРИМЕНЕНИЯ ПРАВА ЕС НАЦИОНАЛЬНЫМИ СУДАМИ СЛОВАЦКОЙ РЕСПУБЛИКИ НА ПРИМЕРЕ ПРЕЮДИЦИАЛЬНЫХ ЗАПРОСОВ}

\author{
Часть первая \\ М. Ондрейчик \\ Общественная организация «Общество для Центральной и Восточной Европы», \\ Братислава, Словацкая Республика
}

\footnotetext{
Введение: автор исследует эффективность применения на практике процедуры, указанной в ст. 267 Договора о функционировании Европейского союза, в национальных судах Словацкой Республики. В статье рассматривается судебная практика Суда ЕС в отношении судебных дел, в ходе которых был направлен преюдициальный запрос в Суд ЕС со стороны судов общей юрисдикции Словацкой Республики. С точки зрения первичного права и судебной практики национальные суды в сотрудничестве с Судом ЕС выполняют обязанности, возложенные на них, с целью обеспечения исчерпывающего и однозначного толкования, применения договоров и соблюдения права ЕС. Автор в статье приводит компаративное сравнение судебной практики в судах общей юрисдикции Словацкой Республики. Методы: использованы общенаучные методы исследования, такие как анализ, сравнение, а также частнонаучный метод исследования - формально-юридический. Результаты: автор анализирует
} 


\section{МЕЖДУНАРОДНОЕ ПРАВО И СРАВНИТЕЛЬНОЕ ПРАВОВЕДЕНИЕ}

работу национальных судов с правом ЕС на примере процедуры преюдициального запроса в судах общей юрисдикции Словацкой Республики. Выводы: на основе приведенной информации можно прийти к заключению, что, кроме Верховного суда Словацкой Республики, все суды общей юрисдикции испытывают проблемы с процедурой, которая касается осуществления преюдициальных запросов, что, в свою очередь, вызывает сомнения в эффективном применении права ЕС словацкими судами общей юрисдикции в случаях, когда, по мнению представителей суда, правовую ситуацию в деле следует считать неоспоримой.

Ключевые слова: Суд ЕС, Договор о функционировании ЕС, Договор о ЕС, национальные суды Словацкой Республики, судебная практика ЕС, преюдициальный запрос.

\section{Введение}

В начале этой статьи следует напомнить, что Суд Европейского союза и национальные суды членов-государств ЕС создали единый судебный механизм. Функции и полномочия этого механизма регулируются прежде всего первичным правом и уточняются судебной практикой Суда ЕС. Исходя из п. 1 ст. 19 Договора о Европейском союзе (далее - ДЕС) хранителями правового порядка и представителями судебной системы ЕС являются: Суд ЕС, суды и трибуналы государств-членов. Кроме того, обязательством Суда ЕС является также обеспечение респектабельности по отношению к автономности правопорядка Европейского союза в том образе, в котором он был создан на основании учредительных договоров [2, п. 66 и 57]. Национальные суды в сотрудничестве с Судом ЕС выполняют обязанности, возложенные на них с целью обеспечения исчерпывающего и однозначного толкования, применения договоров и соблюдения права ЕС. Судебная система ЕС также включает в себя институты правовой защиты и процедуры, предназначенные для совершения проверки законности изданных актов европейскими органами [2, п. 69 и 70]. В соответствии с формулировкой п. 1 ст. 19 ДЕС государствачлены обязаны обеспечивать предоставление средств правовой защиты, которые должны быть удовлетворительными для обеспечения эффективной правовой защиты в областях, охватываемых правом ЕС. Следует также отметить, что государства-члены обязаны в соответствии с принципом искреннего сотрудничества, изложенным в первом абзаце п. 3 ст. 4 ДЕС, обеспечивать на своих территориях надлежащее применение права ЕС и его уважение [2, п. 68], что непосредственно касается национальных судов как части судебной власти каждого государства-члена.

Уровень сотрудничества между национальными судами Словацкой Республики и Судом ЕС возможно определить в рамках ст. 267 Договора о функционировании Европейского союза (далее - ДФЕС). Целью данного нормативного правового акта является обеспечение однозначного и исчерпывающего толкования и применения права ЕС. Данный акт не имеет ничего общего с конкретными спорами, решение которых находится в компетенции национальных судов Словацкой Республики. Процедура по осуществлению преюдициального запроса может быть инициирована только лишь национальным судебным органом $[1 ; 6]$.

С точки зрения Суда ЕС данный процесс следует понимать в качестве особой формы судебного сотрудничества, целью которого является предоставление правовой помощи национальным судам следующим образом: Суд ЕС должен в пределах своих полномочий непосредственно искать взаимоприемлемые решения по делу, с тем чтобы обеспечить единообразное применение и однозначное толкование права ЕС во всех государствах-членах. С точки зрения национальных судов процедуру в рамках ст. 267 ДФЕС можно понимать в виде формы прямого сотрудничества между Судом ЕС и национальными судами, при котором только национальные суды имеют право определять содержание преюдициального запроса [6], который направляют в Суд $\mathrm{EC}$, и устанавливать момент времени, в который его следует отправить (см., например, фразу в п. 28: "the referring court asks essentially whether" [7, п. 19]). В соответствии с данными онлайн-поисковой системы Суда ЕС на сегодняшний день (1 октября 2016 г.) словацкими национальными судами было осуществлено 33 преюдициальных запроса. 
Эффективность

\section{преюдициальных запросов}

\section{по определенным судам общей юрисдикции}

В этой части статьи мы обратим внимание на то, какие суды направляли свои запросы в Суд ЕС, сколько их было отправлено, а также постараемся привести статистику эффективности этих запросов.

На первый взгляд можно сказать, что, кроме Верховного суда Словацкой Республики, процедура осуществления преюдициального запроса была совершена двумя областными судами и четырьмя районными судами (до 1 октября 2016 г.). Однако если мы обратим внимание на то, каким образом было завершено судебное разбирательство в конкретных делах, то мы придем к выводу, что наиболее успешным по количеству положительных результатов является Верховный суд Словацкой Республики (7 положительных из 9). Довольно активным в данной сфере является также Областной суд в г. Прешов, но, по статистическим данным, его баланс не является таким же положительным. До сих пор было зафиксировано только два положительных результата из двенадцати. Это можно объяснить тем, что в этом суде постановление о закрытии дела принималось крайне часто (семь из двенадцати), в двух случаях Суд ЕС отказался заниматься этими делами по причине недопустимости (и в одном случае таковой была рекомендация Генерального адвоката), в другом случае дело было закрыто постановлением по причинам существующей судебной практики. Районный суд в г. Прешов также обладает отрицательной разницей: два положительных результата из пяти.

Статистика по Областному суду в г. Прешов представляет собой наибольший интерес, потому что многих удивляет тот факт, что в этом суде стороны спора часто забирают свои дела из суда, или что этот суд нередко отзывает свои преюдициальные запросы, отправленные в Суд ЕС. В соответствии с $\S 109$ п. 1с) 200/2013 Закона о гражданском судебном производстве, после того как суд осуществляет преюдициальный запрос в Суд ЕС, он должен принять постанов- ление о прекращении дела и ждать, пока Суд ЕС примет решение в рамках ст. 267 ДФЕС. В соответствии с п. 19 «Рекомендаций национальных судов и трибуналов по отношению к инициации предварительных разбирательств» [7, п. 19] надо, чтобы решение отправить преюдициальный запрос было принято в момент достижения национальными судебными процедурами той стадии, на которой национальный суд или трибунал был бы в состоянии полностью определить правовую и фактическую стороны дела, для того чтобы Суд ЕС имел в распоряжении всю необходимую информацию для проверки надлежащего применения права ЕС в судебном разбирательстве национального суда Словацкой Республики. В интересах надлежащей реализации правосудия крайне желательно, чтобы преюдициальный запрос был осуществлен только после того, как обе стороны были услышаны, с целью избежания негативных последствий.

Даже в случае получения национальным судом положительной реакции на свой преюдициальный запрос коммуникация между Судом ЕС и национальным судом может быть проблематичной. В качестве примера можно привести одно из высказываний Генерального адвоката Nils Wahl по делу C-470/12: «Это абсолютно удивительно и прискорбно, что национальный суд, во-первых, не посчитал нужным информировать Суд ЕС о судебно-процессуальных шагах, предпринятых через более чем месяц после направления преюдициального запроса <...> [5, п. 34].

\section{Выводы}

В этой статье мы постарались собрать необходимую информацию для оценки работы национальных судов с правом ЕС. Ответ на вопрос, касающийся эффективности применения права ЕС в национальных судах Словацкой Республики, является проблематичным, поскольку для предоставления полноценной оценки необходимо получить доступ к информации в более крупных масштабах, потому что национальные суды работают с правом ЕС и вне рамок ст. 267 ДФЕС. С другой стороны, то, как национальные суды справляются с процедурой осуществления преюди- 


\section{МЕЖДУНАРОДНОЕ ПРАВО И СРАВНИТЕЛЬНОЕ ПРАВОВЕДЕНИЕ}

циальных запросов, можно считать зеркалом их работы с правом ЕС в целом. Если обратить свое внимание только лишь на эффективность проведения данной процедуры в рамках ст. 267 ДФЕС, можно прийти к следующим выводам:

1. Исходя из статистических данных, кроме Верховного суда Словацкой Республики, все остальные суды испытывают проблемы с осуществлением преюдициальных запросов.

2. Анализ некоторых дел показал, что национальные суды испытывают определенные трудности в отношении сотрудничества и коммуникации с Судом ЕС, что значительно затрудняет вынесение решений по конкретным делам и даже прямо этому препятствует.

3. В контексте сказанного возникает вопрос: насколько хорошо представители национальных судов Словацкой Республики о3накомлены с правом ЕС? На этом месте следует напомнить, что в течение первых лет суды практически не пользовались процедурой отправления преюдициальных запросов или прибегали к ним крайне редко (с 2004 по 2009 г.). Кроме того, удивляет и тот факт, что в Словацкой Республике действуют несколько десятков судов, но на сегодняшний день свои преюдициальные запросы направили в Суд ЕС только семь из них. Второй вопрос, который пока остается открытым: насколько эффективно применяется право ЕС словацкими судами первой инстанции в случаях, когда представители суда считают правовую ситуацию в делах неоспоримой? На эти вопросы ответить сложно, но на основе вышесказанной информации каждый сможет сделать для себя вывод.

4. Все указанные проблемы с большей долей вероятности связаны и с тем, что уровень владения иностранными языками, то есть официальными языками ЕС, в словацких судах не соответствует уровню, который можно считать удовлетворительным для обеспечения эффективного применения права ЕС в государствах-членах [3]. Указанное положение препятствует эффективному ознакомлению судьями и вспомогательным персоналом, работающим в словацких судах, с правовыми нормами ЕС и судебной практикой Суда ЕС.

\section{СПИСОК ЛИТЕРАТУРЫ}

1. Judgment of the Court. Lesoochranárske zoskupenie VLK. C240/09. March 8, 2011 // CJEU. Electronic text data. - Mode of access: http:// curia.europa.eu/juris/document/document.jsf; jsessionid $=9$ ea $7 \mathrm{~d} 2 \mathrm{dc} 30 \mathrm{~d} 57363 \mathrm{~b} 822 \mathrm{af} 784 \mathrm{cefad} 52 \mathrm{a} 46$ c14a249f0.e34KaxiLc3qMb40Rch0SaxyKah90?text= \&docid $=80235$ \&pageIndex $=0$ \&doclang $=\mathrm{EN} \&$ mode $=$ 1 st\&dir $=\&$ occ $=$ first\&part=1\&cid $=231947$. - Title from screen.

2. Opinion delivered pursuant to Article 218(11) TFEU. Opinion 1/09. March 8, 2011 // CJEU. - Electronic text data. - Mode of access: http://eur-lex.europa.eu/ legal - content/EN/TX T/H T M L/? uri= CELEX:62009CV0001\&from=EN. - Title from screen.

3. Opinion of Advocate General Sharpston. Home Credit Slovakia. C42/15, June 9, 2016 // CJEU. Electronic text data. - Mode of access: http:// curia.europa.eu/juris/document/document. jsf?text $=\&$ docid $=179821$ \&pageIndex $=0 \&$ doclang $=$ EN\&mode $=$ req\&dir $=\&$ occ $=$ first $\&$ part $=1 \& \mathrm{cid}=57598$, items 30-34. - Title from screen.

4. Opinion of Advocate General Wahl. Peter Macinský. Case C482/12. November 21, 2013 // CJEU. Electronic text data. - Mode of access: http://curia. europa.eu/juris/document/document.jsf?text=\&docid= $144813 \&$ pageIndex $=0 \&$ doclang $=E N \&$ mode $=1$ st $\&$ dir $=$ \&occ $=$ first\&part $=1 \&$ cid $=318954$. - Title from screen .

5. Opinion of Advocate General Wahl. Pohotovost' s. r. o. Case C470/12. December 12, 2013 // CJEU. - Electronic text data. - Mode of access: http://curia.europa.eu/juris/document/document. jsf;jsessionid $=9 \mathrm{ea} 7 \mathrm{~d} 2 \mathrm{dc} 30 \mathrm{~d} 561 \mathrm{be} 01 \mathrm{c} 778194 \mathrm{~d} 66966 \mathrm{e} 90$ ba27f0ec31.e34KaxiLc3qMb40Rch0SaxuTc3j0?text= $\&$ docid $=145567 \&$ pageIndex $=0 \&$ doclang $=$ SK\&mode $=1$ st $\&$ dir $=\&$ occ $=$ first $\&$ part $=1 \&$ cid $=288501 .-$ Title from screen.

6. Order of the Court. La Pyramide SARL. Case C-378/93. August 9, 1994 // CJEU. - Electronic text data. - Mode of access: http://eur-lex.europa.eu/legalcontent/EN/TXT/HT ML/? uri=CELEX: $61993 \mathrm{CO} 0378 \&$ from $=\mathrm{EN}$. - Title from screen.

7. Recommendations to national courts and tribunals in relation to the initiation of preliminary ruling proceedings. - Electronic text data. - Mode of access: http://eur-lex.europa.eu/legal-content/EN/ TXT/HTML/?uri=CELEX:32012H1 106(01)\&from= SK. - Title from screen.

\section{REFERENCES}

1. Judgment of the Court. Lesoochranárske zoskupenie VLK. C240/09. March 8, 2011. CJEU. Available at: http://curia.europa.eu/juris/document/ 
M. Ондрейчик. Эффективность применения права ЕС национальными судами Словацкой Республики

document.jsf;jsessionid $=9$ ea $7 \mathrm{~d} 2 \mathrm{dc} 30 \mathrm{~d} 57363 \mathrm{~b}$ 822 af784cefad52a46c14a249f0.e34KaxiLc3q Mb40 Rch 0 S a x y Kah 90 ? text $=\&$ docid $=$ 80235\&pageIndex $=0 \&$ doclang $=$ EN\&mode $=1$ st\&dir $=\&$ occ $=$ first\&part $=1 \&$ cid $=231947$.

2. Opinion delivered pursuant to Article 218(11) TFEU. Opinion 1/09. March 8, 2011. CJEU. Available at: http://eur-lex.europa.eu/legal-content/EN/TXT/HTML/ ?uri=CELEX:62009CV0001\&from $=\mathrm{EN}$.

3. Opinion of Advocate General Sharpston. Home Credit Slovakia. C42/15, June 9, 2016. CJEU. Available at: http://curia.europa.eu/juris/document/ document.jsf?text $=\&$ docid $=179821 \&$ pageIndex $=$ $0 \&$ doclang $=\mathrm{EN} \&$ mode $=$ req $\&$ dir $=\&$ occ $=$ first $\&$ part $=$ $1 \& \mathrm{cid}=57598$, items $30-34$.

4. Opinion of Advocate General Wahl. Peter Macinský. Case C482/12. November 21, 2013. CJEU. Available at: http://curia.europa.eu/juris/document/ document.jsf?text $=\&$ docid $=144813 \&$ pageIndex $=$
$0 \&$ doclang $=$ EN\&mode $=1$ st \&dir $=\&$ occ $=$ first $\&$ part $=$ $1 \&$ cid $=318954$.

5. Opinion of Advocate General Wahl. Pohotovost' s. r. o. Case C470/12. December 12, 2013. CJEU. Available at: http://curia.europa.eu/juris/ document/document.jsf; jsessionid=9ea $7 \mathrm{~d} 2 \mathrm{dc} 30$ d561be01c778194d66966e90ba27f0ec31.e34KaxiLc3q Mb40Rch0SaxuTc3j0?text $=\&$ docid $=145567 \&$ page Index $=0 \&$ doclang $=$ SK\&mode $=1$ st \&dir $=\&$ occ $=$ first\&part $=1 \&$ cid $=288501$.

6. Order of the Court. La Pyramide SARL. Case C-378/93. August 9, 1994. CJEU. Available at: http:// eur-lex.europa.eu/legal-content/EN/TXT/HTML/ ?uri=CELEX:61993CO0378\&from $=\mathrm{EN}$.

7. Recommendations to national courts and tribunals in relation to the initiation of preliminary ruling proceedings. Available at: http://eur-lex. europa.eu/legal-content/EN/TXT/HTML/?uri= CELEX:32012H1106(01)\&from=SK.

\section{Information About the Author}

Mikhal Ondreychik, NGO “Society for Central and Eastern Europe”, Veternicová St., 11, 84105 Bratislava, Slovak Republic, ondrejcik@mail.ru.

\section{Информация об авторе}

Михал Ондрейчик, Общественная организация «Общество для Центральной и Восточной Европы», ул. Ветерницова, 11, 84105 г. Братислава, Словацкая Республика, ondrejcik@mail.ru. 